\title{
Role of Urban Agriculture in Improving Household Income and Dietary Diversity: The Case of Bure and Finoteselam Towns, West Gojjam Zone, Amhara National Regional State, Ethiopia
}

\author{
Zebenay Shitaye (Msc) \\ College of Agriculture and Natural resource, department of rural development and agricultural extension, Debre \\ Markos University, p. o box 269, Debre Markos, Ethiopia
}

\begin{abstract}
A study was conducted to investigate the role of Urban Agriculture in improving household income and dietary diversity the case of Bure and FinoteSelam Towns. For study, two Kebeles were selected using purposive sampling techniques based on their potentials and existing trained in urban agriculture. Accordingly, from the two Kebeles, a total of 242 sampled respondents were selected. Both primary and secondary data types were used for this specific study. Survey questionnaires, focus group discussion, key informant interview and personal observation were major data collected methods. The study was analyzed by using SPSS software version 20 by binary logistic model and descriptive statistics. The study also shows the major reasons why urban agriculture practionaier were engaging in the business like to earn additional income (57.6\%), as means of employment opportunities (18.5\%) and other multiple responses (14.1\%). Also inconvenience working place, lack of awareness on the importance of the business and time scarcity were the major reasons of the non urban agriculture practionors for not engaging in the business. According to this study, urban agriculture has statically significant to the enhancement of the dietary urban household in the consumption patterns of diversified types of food items by urban agriculture practisers than non-practionors particularly of tuber roots, vegetables, fruits ,eggs legumes and milks. Inadequate extension supports \& training, shortages \& high costs of inputs and inconvenience the working place were the major production related constraints and also lower prices of products, transportation problems and price manipulations by middle men were the three major market related problems of urban agriculture (UA) in the study area. Specifically, logistic regression analysis revealed respondents' land access, current occupation of the respondents, extension support, credit availability and training as the significant factors determining urban agriculture in the study area. The study concludes the urban farmers produce a variety of vegetables and livestock products for home use and/or market. This UA products particularly dairy business, garden vegetable production, fruits and poultry products played significant role in improving household income and diversifying the dietary intake of both UA practitioners and non-practitioners. Besides these UA has other major economic contributions include employment and income generation for several youth groups in the study towns. To overcome such a problem, policy makers and urban planners should give Special attention and priority support for the implantation and expansion of urban agriculture business in the study towns in particular and the country in general.
\end{abstract}

Keywords: urban agriculture, constraints, non urban agriculture, dietary, engagement, household income

DOI: $10.7176 /$ DCS/9-9-01

Publication date:September $30^{\text {th }} 2019$

\section{INTRODUCTION}

\subsection{Background of the Study}

Urban agriculture can be defined in a simple term as the growing, processing and distribution of food and other products through intensive plant cultivation and animal husbandry in and around cities (Kareem and Raheem 2012). Also, Adeniyi (2011) defined urban agriculture as the practice of food production within the city boundary or on the immediate periphery, which includes the growing of food crops, fruits, trees, herbs, flowers, as well as raising of animals including cattle, poultry, fish, bees and pigs. A number of studies show that the fruit and vegetable intake, as measured in terms of recommended servings per day, is higher among gardeners than among nongardeners. Gardeners ate more vegetables more frequently and they consumed less sweet foods and soft drinks as compared to non- gardener control group(Zezza and Tasciootti, 2010).

Urban agriculture is practiced by about 800 million people globally and has contributed to food security and food safety (UNDP 1996). The practice helped to sustain livelihood of urban and pre-urban low income dwellers in developing countries for many years. It is the source of income, creates employment, and helps to get daily bread from selling of agricultural products in several urban areas UNDP (1997) stated that, urban agriculture enhances the freshness of perishable foods reaching urban consumers, increasing overall variety and the nutritional value of food available.

Zezza\&Tasciotti (2010) agreed that there is a correlation between an active participation of urban household in agricultural activities and greater dietary diversity. There are a number of ways through which urban agriculture can, in principle, have an impact on urban food security especially at household level. 
Urban agriculture contributes by reducing the percentage of the family budget that is spent on food; urban farming makes income available for other expenditures, including health care and education (Staal 1997).

\subsection{Statement of the Problem}

The MDG targets for 2015 were set to get us "half way" to the goal of ending hunger and poverty, with similar proportional goals in other fields. The SDGs are designed to finish the job - to get to a statistical "zero" on hunger, poverty, preventable child deaths and other targets. This approach will call for very different strategies: getting "halfway there" encouraged countries to "do the easiest parts first." Getting to zero requires a real focus on the empowering the poorest and hardest to reach. One of such strategies is UA development.

Urban Agriculture in FinoteSelam and Bure towns played significant contribution in terms of income generation, employment or job creation, and attaining the food security status of several urban poor and female headed households. The Sustainable Development Goals put sustainable, inclusive economic development at the core of the strategy, and address the ability of countries to address social challenges largely through improving their own revenue generating capabilities. It has a direct action against hunger and contributes to poverty reduction. Hence, it should actively be promoted to address the sensitive economic problems of urban communities.

According to Dereje 2007, the urban agriculture policy in Ethiopia was not supportive to urban agriculture progress and thus the practitioners lack support from the concerned stakeholders, and lack extension service, inputs, credit, working places and access to market. Moreover, practitioners provided with inadequate information on production and market related concerns.

Moreover this no study was conducted concerning the role and significance of urban agriculture business towards improving household income, employment generation and ensuring the food security in this specific locality and hence no empirical data is available in this regards.

This research therefore attempted to assess the contribution of urban agriculture in improving household income and dietary diversity.

\subsection{Objectives of the Study}

1.3.1. General objective

The general objective of this study was to assess the contribution of urban agriculture towards improving household income and dietary diversity.

\subsubsection{Specific objectives}

i. To assess the contribution of urban agriculture in enhancing household income

ii. To assess the contribution of urban agriculture in enhancing household Dietary diversity.

iii. To assess production and marketing constraints of urban agriculture in the study area

iv. To analyze determinates of household decision making and engagement in urban agriculture business in the study area.

\subsection{Significance of the Study}

Urban agriculture has the potential to be the main means of achieving adequate dietary diversity, and economic wellbeing particularly for the poor, female headed household and youths who are working in group, hence currently catches the attention of policy-makers in many countries. Thus the output of this study will be used as input for the policy makers and urban planners to consider urban agriculture as an option for livelihood as well as employment opportunity to the urban communities. It will also provide further evidence and literature for those researchers who have interest to conduct a study in related thematic areas.

\subsection{Scope and limitations of the Study}

This study was assessing the contribution of urban agriculture towards improving household income and dietary diversity in randomly selected kebeles of Bure and Finoteselam towns. The research was conducted mainly based on the socio economic information of the sample households that was collected by employing in advance prepared and pretested survey questionnaire. Budget was released just only two months prior to the end of the 2010 E.C budget year. So it was so difficult to manage the budget according to the planned schedule.

\section{METHODOLOGY OF THE STUDY}

\subsection{Description of the Study Area}

This study is designed to be implemented in Finoteselam and Bure towns, these towns are located at about $100 \mathrm{Kms}$ and $72 \mathrm{Kms}$ to the North of Debremarkos town, respectively.

The mean annual perception for Bure and Finoteselam towns is $1450 \mathrm{~mm}$ and $1400 \mathrm{~mm}$ per annum respectively. The mean Temperature ranges from $17^{\circ} \mathrm{C}$ to $27^{\circ} \mathrm{C}$ for Bure and $20-32^{0 \mathrm{c}}$ for Finoteselam and the elevation is 1650m.a.s.l for Bure and 1400 m.a.s.l for Bure. Thus, Bure town is categorized under the wet 'Woina Dega' type of climate, where as Finoteselam is categorized under Kola agro-climate zone. 
According to the information from Bure town administration Office of Agriculture, there are 3017 male and 938 female headed and totally 3955 households in both town with an average family size of 6 persons /family. On the other hand the current total number of households in FinoteSelam town is 4112 including 3707 male and 405 FHHs (Finoteselam town UA development office, 2017).

\subsection{Research Design}

In order to examine the research questions and the practical reality in the study area, the researcher has used the cross sectional research design.

\subsection{Sampling Procedure and Sample Size Determination}

Purposive sampling was used to select the study wereda and Kebeles. A total of 242 respondents were selected using purposive sampling techniques. The total number of sample respondents was determined by using the simplified formula provided by Yemane (1967) cited in Udayakumaraet al. (2010) at 95\% level of confidence interval, with 0.05 level of precision.

Where, $\mathrm{N}=$ total population / sampling frame of the study kebeles,

$$
n=\frac{N}{1+N\left(e^{2}\right)}
$$

$\mathrm{n}=$ Sample size,

$\mathrm{e}=$ level of precision at 0.05 .

Accordingly the sample size was determined as shown below.

Total number of households in these kebeles $(\mathrm{N})=615$ (including 351 in kebele 01 of Bure and 264 kebele 03 of Finoteselam)

$$
\begin{aligned}
& \mathrm{n}=\mathrm{N} / 1+\mathrm{N}(\mathrm{e}) 2, \mathrm{n}=615 / 1+615(0.05) 2 \\
& \mathrm{n}=615 / 1+615 \times 0.0025 \\
& \mathrm{n}=615 / 1+1.5375 \\
& \mathrm{n}=615 / 2.5375 \\
& \underline{\mathbf{n}}=\mathbf{2 4 2}
\end{aligned}
$$

Then Probability Proportional Sampling (PPS) technique was employed in order to draw an appropriate sample size from each kebele.

\subsection{Data Type and Sources}

The study relied on two main sources of data namely, secondary and primary data as well as mixing qualitative and quantitative data type. Primary data was gathered directly from respondents. Secondary data collection was conducted by collecting information from a diverse source of documents and electronically stored information. The qualitative method involves subjective assessment of attitudes, opinions and behaviour whereas the quantitative method is concerned with the generation of data in numeral form.

\subsection{Methods of Data Collection}

Survey Questionnaire: - Structured survey questionnaire was prepared prior to conducting the survey so as to collect valuable data on the socio-economic characteristics of sample households. Focus Group Discussion (FGD): - a check list that to collect valuable information/data was prepared and used.

Key Informant's Interview (KII):- individuals who are knowledgeable about the locally existing constraints, challenges and opportunities were contacted and discussion was held with them.

Personal Observation: - was employed in order to collect supportive data that found difficult to be obtained by other type of data collection methods.

Food Consumption Recall Index/ Format/:- it is a standardized format that developed by WFP in 1996. This format categorized the food items in to twelve fundamental groups in which household were asked to recall the type of food items that they consumed over a period of 24 hours so as to assess their respective diversified type of dietary intakes.

\subsection{Methods of Data Analysis}

Prior to data analysis, the collected data were sorted out, edited, coded, organized, and summarized. Data were analyzed using descriptive statistics and binary logit model. The statistical package for social science SPSS version 20 software was used for data analysis.

\section{Dependent and Independent Variables}

Dependent Variable:-This will take a value $0=$ if the household is not engaged in Urban Agriculture business (and 1= if the household engaged in Urban Agriculture business 
Table 4.Variables Description and Expected Signs

Selected Independent Variables Description on Independent Variables

Sex of the Respondent[SEX]

Age of the Household /AGHHS/

Marital Status of Respondents [MRG]

Household's occupation[OCCUP]

Education Level [EDUC]

Family Size[FAMSIZE]

Extension service [EXTSERVICE]

Land Ownership[LAND]

Loan and credit [CREDIT]

Input /INPUTS/

Water/IRRWATER
The probability of households to be male or female $(1=$ male $2=$ female $)$

The age of the respondent in years

The probability of a household to get married or not

Type and nature of major occupation of the household

Schooling years of households (in class)

Number of persons per HHs

Access to adequate extension support

$0=$ has no access $1=$.Have access

Land ownership/ and usufruct

Household's access to loan/ credit

$0=$ has no access \& 1 have access

Availability of inputs around the site

Availability water for irrigation and

livestock $0=$ Unavailable, 1 Available
Dependent Variables and Expected Sign

Source:-Adopted from literature review

\section{RESULTS AND DISCUSSION}

3.1. Socioeconomic Characteristics of the Respondents

Table 5:- Distribution of respondents by sex

\begin{tabular}{lcccccc}
\hline \multicolumn{1}{c}{ Town } & $\begin{array}{c}\text { Male } \\
\text { Frequency }\end{array}$ & $\mathbf{\%}$ & $\begin{array}{c}\text { Females } \\
\text { Frequency }\end{array}$ & $\boldsymbol{\%}$ & $\begin{array}{c}\text { Total } \\
\text { Frequency }\end{array}$ & $\%$ \\
\hline Bure & 114 & 82.6 & 24 & 17.4 & 138 & 100 \\
FinoteSelam & 82 & 78.8 & 22 & 21.2 & 104 & 100 \\
Total & 196 & 81 & 46 & 19 & 242 & 100 \\
\hline
\end{tabular}

Source: - Own survey result (2018)

Table 5 above revealed that $81 \%$ of the respondents are males and the rest $19 \%$ are females. With regard to their residence those respondents from Bure comprised of 82.6 males and 17.4 females whereas those from Finoteselam comprised of $78.8 \%$ males and $21.2 \%$ females.

Table 6:- Sex of Respondents and Urban Agriculture engagement

\begin{tabular}{lllllll}
\hline & Male & \multicolumn{3}{c}{ Female } & \multicolumn{2}{c}{ Total } \\
& Frequency & $\%$ & Frequency & $\%$ & Frequency & $\%$ \\
\hline UA practitioners & 71 & 77.2 & 21 & 22.8 & 92 & 38 \\
UA Non-Practitioners & 125 & 83 & 25 & 16.7 & 150 & 62 \\
Total & 196 & 81 & 46 & 19 & 242 & 100 \\
\hline
\end{tabular}

Source: Own survey result (2018)

As shown in table 6 above $77.2 \%$ of the UA practitioners are males and the rest $22.8 \%$ are females whereas $83 \%$ of the non-practitioners are males and $16.7 \%$ are females.

Table 7:- Distribution of Respondents by Age

\begin{tabular}{lcccc}
\hline \multicolumn{1}{c}{ Household category } & \multicolumn{2}{c}{ Range } & Mean & Standard deviation \\
& Min & Max & 36.77 & 8.26 \\
UA practitioners & 20 & 58 & 46.71 & 9.03 \\
\hline
\end{tabular}

Source: - Own survey result (2018)

As shown in table 7 above the age of UA practitioners ranges from 20 to 58 with a mean value of 36.77 and standard deviation 8.26 while the age of the non- practitioners ranges from 28 to 68 years with a mean value of 46.71 and standard deviation of 9.03 . 
Table 8:- Education Level of Respondents

\begin{tabular}{lcccccc}
\hline \multicolumn{1}{c}{ Education Level } & \multicolumn{2}{c}{ UA Practitioners } & \multicolumn{2}{c}{ UA Non-Practitioners } & \multicolumn{2}{c}{ Total } \\
& Frequency & $\mathbf{\%}$ & Frequency & \% & Frequency & \% \\
\hline Illiterate & 7 & 2.2 & 27 & 18 & 29 & 12 \\
Read and Write & 12 & 13 & 57 & 38 & 69 & 28.5 \\
Elementary/Grade1-8/ & 26 & 26 & 45 & 30 & 71 & 29.3 \\
High School & 24 & 24 & 5 & 3.3 & 29 & 12 \\
Preparatory and above & 28 & 28 & 16 & 10.7 & 44 & 18.2 \\
Total & 92 & 100 & 150 & 100 & 242 & 100 \\
\hline
\end{tabular}

Source:-Own survey result (2018)

As shown in table 8 above majority of the Urban agriculture practitioners (28\%) are preparatory and above in their academic level followed by elementary /grade1to 8/, high school read and write and illiterate with their share of $26 \%, 24 \%, 13 \%$ and $2.2 \%$ respectively whereas the academic level of the non-practitioners comprised of $29.3 \%$ elementary /Grade 1 to 8/, 28.5 able to read and write, $18.2 \%$ preparatory and above, $12 \%$ high school and again $12 \%$ illiterates.

Table 9:- Marital status of respondents

\begin{tabular}{lcccccc}
\hline Marital status & \multicolumn{2}{c}{ UA Practitioners } & \multicolumn{2}{c}{ UA Non-Practitioners } & \multicolumn{2}{c}{ Total } \\
& Frequency & $\%$ & Frequency & $\%$ & Frequency & $\%$ \\
\hline Single & 5 & 5.4 & 8 & 4 & 11 & 4.4 \\
Married & 83 & 90.2 & 139 & 92.7 & 222 & 91.7 \\
Divorced & 1 & 1.1 & 0 & 0 & 1 & 0.4 \\
Widowed & 3 & 3.3 & 5 & 3.3 & 8 & 3.5 \\
Total & 92 & 100 & 150 & 100 & 242 & 100 \\
\hline
\end{tabular}

Source:-Own survey result (2018)

As table 9 indicated $90.2 \%$ of UA practitioners were married whereas $5.4 \%, 3.3 \%, 1.1 \%$ of AU practitioners were single, widowed and divorce, respectively. Also $92.7 \%, 4 \%$ and $3.3 \%$ of non UA were married, single and widowed, respectively.

3.2. Households' Reasons for Engaging and Not Engaging in UA Businesses

Table 10:- Reasons of urban agriculture practitioners for engaging in the business

\begin{tabular}{lccc}
\hline \multicolumn{1}{c}{ Reason } & Frequency & Percent & Rank \\
\hline Means of employment/ to get employed/ & 17 & 18.5 & 2 \\
To earn additional family income & 53 & 57.6 & 1 \\
Personal interest/ hobby/ & 9 & 9.8 & 4 \\
Multiple responses & 13 & 14.1 & 3 \\
Total & 92 & 100 & - \\
\hline
\end{tabular}

Source: - Own survey result (2018)

As shown in table 10 above $57.6 \%$ of the UA practitioners engaged in the business as means of earning additional income for their livelihood and $18.5 \%$ engaged in this business to get themselves employed. From this the researcher can concluded that majority of the respondents were engaged in urban agriculture in order to earn additional family income and as a means of employment opportunities.

Table 11:-Reasons of the non- urban agriculture Practitioners for not engaging in the business

\begin{tabular}{lccc}
\hline \multicolumn{1}{c}{ Reasons } & Frequency & Per Cent & Rank \\
\hline Lack of interest & 20 & 13.5 & 4 \\
Inconvenience of the working place & 28 & 18.6 & 2 \\
Lack of awareness on the importance of the & 33 & 22 & 1 \\
business & & & 3 \\
Time scarcity & 25 & 16.6 & 7 \\
Labour shortage & 11 & 7.3 & 6 \\
Lack of water around the home steeds & 12 & 8 & 5 \\
unavailability and high cost of inputs & 13 & 8.7 & 8 \\
Multiple responses & 8 & 5.3 & - \\
Total & 150 & 100 & \\
\hline
\end{tabular}

Source: - Own survey result (2018)

As shown in table 11 above, the major reasons for their not participating in urban agricultures are lack of awareness on the importance and benefits of the business being considering it as silly or useless task (22\%), the inconvenience of their homestead to run the business that being having no vacant space (18.6\%) and time scarcity being busy by other responsibilities $(16.6 \%)$. 


\subsection{Contribution of Urban Agriculture in Enhancing Household Income}

UA improves a household's access to food during times of shortage, instability or uncertainty (Bush, 2010; Zezza\&Tasciotti, 2010). Similarly UA has significant contribution to enhance household income in Bure and FinoteSelam towns too as discussed based on table 13 below.

Table 13:- Income level of households from urban agriculture and other sources

\begin{tabular}{lccccc}
\hline & \multicolumn{5}{c}{ Annual Income level of Households } \\
Household category & $\begin{array}{c}\text { Mean } \\
\text { From UA }\end{array}$ & $\begin{array}{c}\text { From other } \\
\text { sources }\end{array}$ & $\begin{array}{c}\text { Weighted } \\
\text { total mean }\end{array}$ & $\begin{array}{c}\text { Standard } \\
\text { deviation }\end{array}$ & P value \\
\hline UA practitioners & 79673.91 & 50488.63 & 96478.26 & 33240.87 & $0.000^{* * *}$ \\
UA Non - practitioners & 0 & 64782.26 & 64782.26 & 21182.73 & $0.033^{* * *}$ \\
\hline
\end{tabular}

$* * *$ and $* * *$ Significant at $\mathrm{P}<0.05$ probability level

Source: - Own Survey Result (2018)

Table 13 above revealed that almost all the UA practitioners earned a mean annual income of Br.96478.6 with a standard deviation of 33240.87 implying that there is a great income difference between groups based on the nature of the business. This income is generally earned from both UA and Non UA businesses including Br.79673.91 and Br. 50488.63 from UA and non-agricultural Business activities respectively. On the other hand the non- practitioners earned a mean annual income of Br.64782.26 with a standard deviation of 21182.73 totally from non UA business activities.

3.4. Urban Agriculture and Household Dietary Diversity

Table 14: Households' Dietary Intake over 24hrs of Study Period

\begin{tabular}{|c|c|c|c|c|c|c|c|c|c|c|}
\hline \multirow{4}{*}{ Food Groups } & \multirow{2}{*}{\multicolumn{4}{|c|}{ UA practitioners }} & \multicolumn{4}{|c|}{ UA non Practitioners } & \multirow{4}{*}{$\mathbf{X}^{2}$} & \multirow{4}{*}{$P$ value } \\
\hline & & & & & & & & & & \\
\hline & \multicolumn{2}{|c|}{ Yes } & \multicolumn{2}{|c|}{ No } & \multicolumn{2}{|c|}{ Yes } & \multicolumn{2}{|c|}{ No } & & \\
\hline & Freq & $\%$ & Freq & $\%$ & Freq & $\%$ & Freq & $\%$ & & \\
\hline Cereals & 92 & 100 & 0 & 0 & 150 & 100 & 0 & 0 & 1.001 & 0.999 \\
\hline White and tuber roots & 36 & 39.1 & 56 & 60.9 & 12 & 8 & 138 & 92 & 34.755 & $0.000 * * *$ \\
\hline Vegetables & 54 & 58.7 & 38 & 41.3 & 23 & 15.3 & 127 & 84.7 & 51.954 & $0.000 * * *$ \\
\hline Fruits & 21 & 22.8 & 71 & 77.2 & 9 & 6 & 141 & 94 & 14.866 & $0.000 * * *$ \\
\hline Meat & 12 & 13 & 80 & 87 & 3 & 2 & 147 & 98 & 1.962 & 0.611 \\
\hline Eggs & 12 & 13 & 80 & 87 & 24 & 16 & 126 & 84 & 10.394 & $0.024 * *$ \\
\hline Legumes, Nuts and Seeds & 32 & 34.8 & 60 & 65.2 & 72 & 48 & 78 & 58 & 1.835 & $0.101^{*}$ \\
\hline Milk and Milk Products & 21 & 22.8 & 71 & 77.2 & 38 & 25.3 & 112 & 74.7 & 194 & $0.012 * *$ \\
\hline Fish and Other Sea Food & 0 & 0 & 92 & 100 & 0 & 0 & 150 & 100 & 0.194 & 0.999 \\
\hline Oils and Fats & 87 & 94.6 & 5 & 5.4 & 84 & 56 & 66 & 44 & 0.910 & 0.100 \\
\hline Sweets & 41 & 44.6 & 51 & 55.4 & 26 & 17.3 & 124 & 82.7 & 1.122 & 0.109 \\
\hline $\begin{array}{l}\text { Spices, Condiments and } \\
\text { Beverages }\end{array}$ & 205 & 27.2 & 67 & 72.8 & 8 & 5.3 & 142 & 94.7 & .197 & 0.100 \\
\hline
\end{tabular}
Beverages

*** and *** Significant at $\mathrm{P}<0.05$ probability level, Source: - Own Survey Result (2018)

Table 14 above revealed that UA has statistically significant contribution to the enhancement in the dietary diversity urban households, implying that there is significant improvement in the consumption pattern of diversified type of food items by UA practitioners than the non- practitioner ones particularly of tuber roots, vegetables, fruits, egg, legumes and milk. On the other hand the result of the study revealed that there is no significant difference between the UA practitioners and non-practitioners in the consumption pattern of other food groups including cereals, legumes(nuts and seeds), Fish and Other sea foods, oils and fats, and spices(condiments and beverages). This is because the study areas are known by cereal production particularly by the production of the most staple crop Teff from which the most commonly consumed cultural food 'enjera' is prepared. Therefore, households of the study are whether UA producers or non-producers consume 'enjera' which is prepared from the cereal 'teff' and hence there is no variation in the household's consumption pattern of cereals in the study town.

\subsection{Production and Market Constraints of Urban Agriculture}

In most cities in developing countries, an important part of urban agricultural production is for self-consumption, with surpluses being traded. However, the importance of the market-oriented urban agriculture, both in volume and economic value, should not be under estimated. 


\begin{tabular}{|c|c|c|c|}
\hline Production Constraints & $\begin{array}{c}\text { Response } \\
\text { (frequency) }\end{array}$ & $\%$ & Rank \\
\hline Inconvenience of the working place & 15 & 27.2 & 3 \\
\hline $\begin{array}{l}\text { Shortage and high cost of inputs such as seeds, fertilizer and improved } \\
\text { feed) }\end{array}$ & 33 & 35.9 & 2 \\
\hline Inadequate extension support and training & 41 & 44.7 & 1 \\
\hline Health related problem (unpleasant smell, pollution). & 12 & 13 & 6 \\
\hline $\begin{array}{l}\text { Infrastructures (electric power, mobile network and market } \\
\text { information,etc) }\end{array}$ & 17 & 18.5 & 5 \\
\hline Multiple response & 19 & 20.7 & 4 \\
\hline Total & 92 & 100 & - \\
\hline
\end{tabular}

Source:-Own survey result (2018)

As shown in table 15 above the UA practitioners have been challenged by several production constraints. As of their response inadequate extension support and training unavailability (47\%), Shortage \& high cost of inputs $(35.9 \%)$ and inconvenience of the working site $(27.2 \%)$ are the three major constraints identified by the respondents. The result of the focus group discussion also showed that the unpleasant smell from UA firms particularly of the poultry and dairy farms have been reported by the nearby community members a serious cause for respiratory diseases such as bronchitis asthma and hence was considered as a source of conflict between neighbourhoods.

Table16:-Market related constraints

\begin{tabular}{lccc}
\hline \multicolumn{1}{c}{ Market Related constraints } & Frequency & Per cent & Rank \\
\hline Perish ability of products & 8 & 8.5 & 5 \\
Lesser of demand for the produces & 5 & 5.4 & 6 \\
Lower prices for the products & 41 & 44.6. & 1 \\
Lack of proper market place & 9 & 9.8 & 4 \\
Price manipulation by middle me & 11 & 11.9 & 3 \\
Transportation problem & 12 & 13 & 2 \\
Presence of competitors & 2 & 2.2 & 8 \\
Multiple responses & 4 & 4.4 & 7 \\
Total & 92 & 100 & - \\
\hline
\end{tabular}

Source:-Own survey result (2018)

As shown in table 16 , the most challenging problem as ranked first by $44.6 \%$ of the respondents is lower price for they produces. Transportation problem, price manipulation by middle men and lack of proper market place took the second, third and fourth ranks as prioritized by $13 \%, 11.9 \%$ and $9.8 \%$ of the UA practitioner respondents.

3.6. Determinants of Household's Engagement in Urban Agriculture Business Table 17:- Result of the Binary logit Model

\begin{tabular}{lccc} 
& Dependent variable: Household's engagement in UA business & \\
\hline \multicolumn{1}{c}{ Variables } & $\mathrm{B}$ & Sig. & Exp(B) \\
\hline Sex & -.979 & 0.236 & .376 \\
Age & .159 & 0.900 & 1.173 \\
Marital status & -1.703 & 0.930 & .182 \\
Education & -1.000 & 0.106 & .368 \\
Land access and ownership & 1.680 & $0.000^{* * *}$ & 5.363 \\
Current occupation & 1.430 & $0.001^{* *}$ & 4.178 \\
Extension support & .838 & $0.000^{* * *}$ & 2.312 \\
Water availability & 6.092 & 0.124 & 442.418 \\
Training & -3.803 & $0.000^{* * *}$ & .022 \\
Credit availability & -.748 & $0.000^{* * *}$ & .473 \\
Inputs availability and cost & -.172 & 0.402 & .842 \\
Overall statistics & -3.093 & 0.000 & .045 \\
\hline
\end{tabular}

.*,**, and ***Significant at $\mathrm{P}<0.05$ probability level, Source:-Survey result 2018

The result of binary logistic regression analysis shows that, at $5 \%$ level of significance, land ownership, nature of occupation, access to training, access to extension service and access to credit were significant factors towards urban agriculture. 


\section{Conclusions}

The purpose of this study was to provide empirical evidences on the roles of urban agriculture in improving household income and dietary diversity. The role of urban agriculture in household income and dietary diversity and the socio-economic challenges in relation to urban farming were investigated. UA products particularly dairy businesses, garden vegetable production, fruits and poultry products played significant role in improving household income and diversifying the dietary intake of both UA practitioners and non-practitioners. Besides these UA has other major economic contributions include employment and income generation for several youth groups in the study towns. However the urban agriculture practitioners in the towns have been challenged by several production and market related constraints.

The result of the logit model also showed that land access and ownerships, major occupation of the household, access to extension service, provision of training and availability of loan/credit services have statistical significance in determining households' decision making to engage in urban agriculture business activity at a significant level of 0.05 .

\section{Recommendation}

All concerned stakeholders including the extension personnel, Subject matter specialists, higher level agricultural officials, local leader and politician should strive to create awareness on the importance and benefits of UA through using mass media, posters, leaflets and other extension methods.

Farmers' organisations is essential because most urban farmers are poorly organized, and if so mostly in an informal way, and thus lack channels and power to voice their needs.

$\square$ Formulation of Urban farmer associations and facilitation of Loan and credit services as well as introduction of improved technologies such as drip irrigation and creating better access to market should be given due emphasis by the concerned stake holders.

\section{REFERENCES}

$\rightarrow$ Bure town Office of Agriculture 2017 annual report

$\rightarrow$ Dereje (2007) Role of urban Agriculture for enhancing Household income and food security.

$\rightarrow$ FAO 1999, 24 hours household's dietary intake registration standardised format

$\rightarrow$ Finoteselam town office of Agriculture annual 2017 report

$\rightarrow$ Kareem \&Raheem (2012). A review of urban Agriculture as a tool for building food security in Nigeria challenges \& policy

$\rightarrow$ RUAF 2007. What is urban agriculture? http://www.ruaf.org/node/512 (referenced at May 4,2007).

$\rightarrow$ RUAF 2007. Why is urban agriculture important? http://www.ruaf.org/node/513 (referenced at Sustainable Cities.

$\downarrow$ Staal1997 Urban Agriculture for Employment Generation, Enhancing Household Income and Food Security

$\rightarrow$ UNDP (UN) 1996) the second International Colloquium of majors on Governance for sustainable Growth \& Equity, New York UN.

$\uparrow$ United Nation Development Program (UNDP) and FAO (1996). Urban Agriculture: Food, Jobs and Volume One. New York: UNDP.

$\rightarrow$ Zezza\&Tasciotti (2010) Urban Agriculture, poverty and Food Security: Empirical evidence from a sample of developing countries, Rome, Italy FAO 